\section{Acknowledgements}

The authors thank Dr M. Riccio and Dr W. Shanahan, Consultant Psychiatrists, for their advice and assistance.

\section{References}

Black, M. E., Scheuer, M. A., Victor, C., Benzoval, M. \& JUDGE, K. (1991) Utilisation by homeless people of acute hospital services in London. British Medical Journal, 303, 958-961.
BROTHWOOD, J. (1965) The work of a psychiatric emergency clinic. British Journal of Psychiatry, 111, 631-634.

HuCKLE, P. \& Nolan, M. (1992) Referrals to the emergency assessment clinic, Whitchurch Hospital, Cardiff. Psychiatric Bulletin, 16, 82-83.

Katschnig, H. (1983) Social environment of the psychic crisis situation. Weiner Klinische Wochenschrift, 95/Supp., 145, 6-9.

LiM, M. H. (1983) A psychiatric emergency clinicAttendances over six months. British Journal of Psychiatry, 143, 460-466.

Psychiatric Bulletin (1993), 17, 86-88

\title{
Fire risk: assessment and management in long-term psychiatric patients
}

\author{
Michael Phelan, Clinical Lecturer, PRiSM (Psychiatric Research in Service \\ Measurement), Institute of Psychiatry, De Crespigny Park, London SE5 8AZ; and \\ Nigel Fisher, Consultant Psychiatrist, Springfield University Hospital, \\ 61 Glenburnie Road, London SW17 7DJ
}

Many mental disorders are associated with an increased risk of fire setting. As a result, its assessment and management is an important part of the management of people with psychiatric disorders. As more patients are managed in the community, away from the protection of high levels of hospital staff and fire regulations, such assessments are vital to ensure appropriate and safe placement. The presence of fire regulations in hostels offers only limited protection. Further, as residences with four people or less are not subject to fire regulations, assessment by psychiatric staff may have to extend to the fabric of the placement. Despite psychiatric hostels tending not to accept patients who are 'a fire risk', figures suggest that fires in hostels are common. One health authority reported 26 fires in hostels over 12 months (Moxom, personal communication).

Psychiatric research and clinical attention has tended to focus on deliberate fire setting, usually within a forensic setting (e.g. Soothill, 1990). Such behaviour has been described in patients suffering from a wide range of psychiatric disorders, and is frequently related to patient's social deficits (Geller, 1987). A small proportion of deliberate fire setters fulfil the specific DSM-III-R diagnostic criteria for pyromania (American Psychiatric Association, 1987), which include having a fascination with fire and intense pleasure, gratification or relief, when setting fires. In marked contrast, accidental fire setting in psychiatric patients is widely ignored and standard psychiatric textbooks pay scant, if any, attention to the assessment of fire risk outside the forensic setting. A recent study (Barker et al, 1991) demonstrated that accidental fire setting is a common problem among patients in hospitals. The authors examined fire incidents in two psychiatric hospitals over four years. During this period $49(34 \%)$ of the 143 fires were accidental. In comparison, $59(41 \%)$ of the fires were deliberate and in the remaining 35 $(25 \%)$ fires the cause was not known. Comparative figures are not available for patients living outside hospital, but it is to be expected that accidental fires constitute a similar if not larger proportion of the total fires among patients in community settings.

\section{Assessment}

We suggest an approach to assessing fire risk that examines both individual and environmental factors (see Table I). When assessing individual fire risk, the emphasis should be on behaviour and disabilities rather than on diagnostic categories. This approach helps to draw attention to the increased risk in all psychiatric patients. It is vital that the impact of physical, psychological, and social disabilities on at risk behaviours is assessed in the context of the individual's natural environment. This assessment may be readily included in the assessment of activities of daily living activities. Involvement of the members of the multidisciplinary team is useful to ensure that the full range of activities is covered. Attention must also be paid to any previous history of deliberate or 
TABLE I

Factors in fire risk assessment in psychiatric patients

\begin{tabular}{|c|c|c|c|}
\hline \multicolumn{3}{|c|}{ Factors in the individual } & \multirow{3}{*}{$\begin{array}{l}\text { Environmental } \\
\quad \text { factors }\end{array}$} \\
\hline \multirow[b]{2}{*}{ Behaviour } & \multicolumn{2}{|c|}{ Disabilities } & \\
\hline & Psychiatric & Physical & \\
\hline $\begin{array}{l}\text { Smoking } \\
\text { Cooking } \\
\text { Deliberate fire } \\
\text { setting }\end{array}$ & $\begin{array}{l}\text { Distractability } \\
\text { Apathy } \\
\text { Psychotic experiences } \\
\text { Memory impairment } \\
\text { Suicidal ideation } \\
\text { Disinhibition }\end{array}$ & $\begin{array}{l}\text { Tremor } \\
\text { Neuropathy } \\
\text { Ataxia } \\
\text { Visual } \\
\quad \text { impairment } \\
\text { Sedation }\end{array}$ & $\begin{array}{l}\text { Poor housing } \\
\text { Poor state of } \\
\text { repair of cooking \& } \\
\text { heating equipment } \\
\text { Accumulation of } \\
\text { rubbish }\end{array}$ \\
\hline
\end{tabular}

accidental fire setting. It is our impression that deliberate fire setting is usually well documented in psychiatric notes, but accidental incidents are frequently not recorded. Previous incidents, if possible, should be studied in order to try and ascertain likely causes and any patterns in an individual patient.

An assessment of fire risk in an individual is not complete unless attention is paid to the person's current, or in the case of patients soon to be discharged, future environment. It is self evident that the assessment must extend beyond the ward setting. Poverty and apathy result in houses and flats in a poor state of repair, and potentially lethal electrical and gas appliances; while social disabilities may lead to a dangerous accumulation of rubbish, which may be a significant fire hazard. Such assessments may lead the psychiatrist into uncharted territory. Although most psychiatrists would not consider examining electrical kettles as part of their professional role, they may be the only professionals to visit patients at home, and therefore the only people who are in a position to prevent a potential fire.

Once individuals are identified as being a fire risk, the ongoing assessment of that risk must become a regular component of their clinical review, with the status of their fire risk being accurately updated and documented. Such documentation will help to protect staff in any investigations following fire incidents, as well as being important clinically. However simply documenting that a patient is a fire risk may result in community placements being reluctant to accept the individual. As a result the main consequence of the risk being identified and documented will be that the patient is unable to leave hospital. It is therefore vital to include a management plan focusing on strategies to reduce that risk.

\section{Management}

When managing fire risk it is important to recognise that we are all at some risk from fire. As a conse-
TABLE II

Potential strategies for reducing individual fire risk

\section{Changing behaviour}

Reduction and/or modification of smoking habits

Training in cooking skills/provision of meals on wheels

Training and practice in fire drills

Training in use of extinguishers and fire blankets

Reduction in alcohol and drug use

\section{Disabilities}

Avoidance of drug induced sedation

Use of anti-cholinergics for drug induced tremor and

blurred vision

Provision of spectacles and hearing aids

\section{Environment}

Use of large sand filled ash-trays

Testing of household appliances

Cleaning up of household rubbish and flammable materials

Fire resistant clothes, bedding and furniture

Smoke detectors

Fire extinguishers/fire blankets

Regular checking of fire exits

quence our interventions should be directed at reducing this risk in patients to an acceptable level, rather than trying to eliminate the risk entirely. In any case the infringement of personal liberties, and the resources required to offer complete protection usually mean that it is not a feasible long-term option.

At a group level all patients should be educated about fire hazards. It is anomalous that hospital staff are expected to regularly attend fire lectures, but that such teaching is rarely offered to patients. In particular when patients move accommodation they need to be informed about fire procedures, fire extinguishers, doors, and escapes. At an individual level the nature of specific interventions will depend on the assessment, and as with the assessment 
cover the areas of behaviour, disability, and environment. A range of interventions is listed in Table II, and they are illustrated by the following case vignette.

A 54-year-old woman, with chronic schizophrenia, was living in a psychiatric hostel. The staff of the hostel reported that they had recently noticed holes in her clothes, caused by cigarette burns, and were concerned about her safety, as well as the risk to the other residents. They complained that all attempts at trying to stop her smoking had failed, and they did not know what else could be done. The woman herself was very vague about the burns, and did not appear to appreciate the danger. Physical examination revealed no peripheral neuropathy or tremor, but when asked she did say that her eyesight had deteriorated, and this was confirmed by subsequent testing. In addition hostel staff reported that she appeared to be more drowsy in the evenings, having seen a new doctor in the clinic who had changed her medication. She was fitted with new glasses, which she said helped her to watch television, and her medication was reduced. As the level of supervision at the hostel was lowest in the evening, this was the time that she was felt to be most at risk. The staff therefore provided her with a larger ashtray, which she was rewarded for using in the evenings. It was not clear which of these interventions was the most effective, but no further burns were seen, and the woman was happy that she was no longer nagged about stopping smoking.

This case illustrates how a number of interventions may be needed to reduce fire risk in any one patient.
Even if one approach, such as getting someone to stop smoking, is not possible there will usually be some other ways in which they can be helped.

\section{Conclusions}

Psychiatrists have a responsibility to increase the level of awareness of fire risk in psychiatric patients, as well as assessing risk in individual patients. As disabled patients are increasingly managed outside well staffed hospital settings, there is a potential for patients to be at a greater risk from fire, as well as local communities being put at risk. This needs to be offset by greater vigilance by staff, in order to avoid tragedy.

\section{References}

American Psychiatric Association. (1987) Diagnostic and Statistical Manual of Mental Disorders (3rd edition revised (DSM-III-R)). Washington DC: APA.

BARKER, A., Forshaw, D. \& Moxom, T. (1991) Four-year retrospective survey of fire incidents in a psychiatric hospital. Health Trends, 23, 31-32.

GeLleR, J. L. (1987) Fire setting in the adult psychiatric population. Hospital and Community Psychiatry, 38, 501-506.

SoOthlll, K. (1990) Arson. In Principles and Practice of Forensic Psychiatry (Eds. R. Bluglass and P. Bowden). London: Churchill Livingstone.

\section{Psychiatrists able to assist patients who cannot speak English}

The College receives regular enquiries from members of the College and general practitioners regarding patients who are unable to speak English. We are asked if we can give the name of a psychiatrist able to communicate with patients in their own language.

We maintain a list of members who are fluent in languages other than English. This list is also forwarded to the central offices of the Mental Health Act Commission.
At present, we are having particular difficulty in identifying members who speak Chinese, Gujarati, Bengali, Sudanese, Arabic, Farsi, Somalian and Swahili. I should be grateful if any member who is able and willing to help in this way could write to me giving the relevant particulars, (language spoken, contact address and telephone number) so that this list can be expanded.

VANESSA CAMERON The Secretary 